Cahiers $d u$ MONDE RUSSE

\section{Cahiers du monde russe}

Russie - Empire russe - Union soviétique et États indépendants

$43 / 4 \mid 2002$

Intellectuels et intelligentsia

\title{
Oleg Kharkhordin, The collective and the individual in Russia
}

Nathalie Moine

\section{OpenEdition}

Journals

Édition électronique

URL : https://journals.openedition.org/monderusse/4065

DOI : 10.4000/monderusse.4065

ISSN : $1777-5388$

Éditeur

Éditions de l'EHESS

Édition imprimée

Date de publication : 30 décembre 2002

ISBN : 2-7132-1796-2

ISSN : $1252-6576$

Référence électronique

Nathalie Moine, «Oleg Kharkhordin, The collective and the individual in Russia », Cahiers du monde russe [En ligne], 43/4 | 2002, mis en ligne le 18 juin 2009, consulté le 03 septembre 2022. URL : http:// journals.openedition.org/monderusse/4065; DOI : https://doi.org/10.4000/monderusse.4065

Ce document a été généré automatiquement le 3 septembre 2022.

Tous droits réservés 


\title{
Oleg Kharkhordin, The collective and the individual in Russia
}

\author{
Nathalie Moine
}

\section{RÉFÉRENCE}

Oleg KHARKHORDIN, The collective and the individual in Russia. Study of practices. Berkeley, University of California Press, 1999, 406 p.

1 La notion d'«individu» dans la société soviétique, et singulièrement à l'époque stalinienne, occupe une place croissante dans les recherches actuelles sur l'histoire du régime bolchevik. Pour autant, les processus d'individualisation à l'époque stalinienne ont été soulignés depuis déjà bien longtemps, aussi bien par les « totalitaristes » que les "révisionnistes». Ce qui importe désormais, c'est de passer à l'étude précise des pratiques, comme l'indique clairement le titre de l'ouvrage d'oleg Kharkhordin. Les travaux de Foucault sur la construction du moi dans le monde occidental nourrissent l'armature théorique de l'auteur, qui propose de comprendre les spécificités du moi « soviétique » à la lumière du moi « occidental ».

2 L'étude se veut de long terme, dans les faits elle se place sur deux échelles : le temps long est utilisé pour l'analyse du discours et des pratiques religieuses, et l'auteur n'hésite donc pas à remonter aux sources du christianisme oriental. Alors que l'homme occidental est devenu un "animal confessant », selon Foucault, les pratiques de subjectivation issues de la spiritualité orthodoxe reposent essentiellement sur la pénitence publique, l'orthodoxie accordant une place beaucoup moins grande à la confession, de même que les dirigeants soviétiques banniront ses formes laïcisées comme la psychanalyse et développeront une certaine méfiance à l'égard de pratiques comme la tenue de journaux intimes. De fait, le regard du groupe est le second élément central de la culture orthodoxe, qui parvient à l'objectivation de l'individu par la surveillance mutuelle entre pairs, que l'on trouve aussi bien dans les règles du cénobitisme que dans la culture du mir paysan. 
3 L'importance qu'il prête aux pratiques orthodoxes ne conduit pas pour autant l'auteur à affirmer une parfaite continuité avec la période soviétique, d'autant que les pratiques réelles de l'orthodoxie au $\mathrm{XIX}^{\mathrm{e}}$ siècle et à la veille de la révolution sont traitées de façon très allusive. Si une généalogie est esquissée, Oleg Kharkhordin n'en affirme pas moins la rupture décisive constituée par la révolution d'Octobre dans l'émergence d'un « moi » à la fois objet et sujet et la nouveauté du moi « soviétique».

4 On en vient à la seconde échelle d'analyse, celle de l'époque soviétique dans son ensemble, même si deux périodes sont plus particulièrement travaillées, celle des années 1930 et la décennie khrouchtchévienne. La nouveauté tient à la combinaison de pratiques, en partie héritées, mais aussi à l'ampleur de la démarche des bolcheviks. Lélément central de l'analyse pour comprendre les processus d'individualisation et d'individuation à l'époque soviétique est, paradoxalement d'un point de vue occidental, le groupe, spécifiquement le « kollektiv». L'individu soviétique existe bel et bien, en tant que sujet responsable, susceptible d'accomplir de façon permanente un travail sur soi de perfectionnement et de mise en actes des préceptes du communisme, de même qu'il est reconnu en tant qu'objet de connaissance et de contrôle. Cependant, cette existence du moi ne fait sens qu'au sein et en relation avec le collectif, et plus particulièrement avec le kollektiv, alors que le moi occidental s'est constitué autour des notions d'autonomie individuelle et de vie privée. Kharkhordin s'interroge donc sur cette notion de kollektiv, terme omniprésent de la culture soviétique, mais dont il montre l'émergence problématique au début $\mathrm{du} \mathrm{xx}^{\mathrm{e}}$ siècle puisqu'il n'apparaît pas dans un dictionnaire de langue russe avant 1934. C'est par la conjonction funeste de la dénonciation, de soi ou des autres, de l'exclusion (la purge) et du rôle devenu prédominant dans les années 1930 du kollektiv que Khakhordin explique la spirale infernale de la Grande Terreur, comme forme extrême à la fois de l'approche individuelle et du rôle de surveillance joué par les membres du kollektiv, alors que la remontrance, étape intermédiaire entre auto-critique et purge, disparaît temporairement, au profit de l'obli@enie, dénonciation publique de ses fautes ou de celle des autres.

5 Alors que la focalisation sur la décennie des années 1930, au cours de laquelle l'émergence de l'homme soviétique en tant qu'individu serait devenu un phénomène de masse, s'inscrit dans une production actuelle florissante ${ }^{1}$, l'importance que Kharkhordin accorde aux années 1950-1960 devrait éveiller particulièrement l'intérêt du lecteur. Il montre en effet que la période khrouchtchévienne, si elle correspond effectivement à un fonctionnement moins oppressif, ne se caractérise pas moins par un système de surveillance horizontale mutuelle de plus en plus généralisé et intrusif. Certains exemples développés sont particulièrement convaincants : le retour des patrouilles de volontaires chargés de suppléer la milice, dont le rôle de contrôle social semble infini, en particulier à l'égard de comportements jugés déviants, comme la façon de s'habiller ou de danser, ce qui rendrait certaines pratiques dandys finalement plus difficiles à assumer qu'à l'époque du stalinisme finissant, ou la remise à l'honneur des tribunaux de camarades chargés avant tout de sermonner le collègue de travail ou le voisin de palier. De plus en plus, la formation de kollektivs devient universelle, et atteint des zones de sociabilité non officielle. Piliers du pouvoir, ces derniers deviennent alors le moteur de l'ensemble de la société, y compris chez ses éléments critiques.

6 L'ouvrage de Kharkhordin s'attache ainsi, avec une grande ambition, à expliciter les fondements de la société soviétique. La lecture proposée ne manque pas de pertinence mais les modes de démonstration pourront laisser perplexe. Se fondant sur des textes 
très variés, allant des textes de spiritualité du Moyen Âge aux instructions sur la manière de mener à bien les purges dans le parti ou au règlement des patrouilles de volontaires en passant par les écrits de Makarenko, l'auteur interroge des textes qui, pour n'être pas de pure théorie, n'en sont pas moins des discours sur les pratiques, certes très concrets, mais en légère contradiction avec le projet annoncé. L'insistance sur la continuité des notions est salutaire, mais, de ce fait, plus convaincante sur le relatif court terme de l'époque soviétique que sur la filiation avec l'orthodoxie, l'hétérogénéité des textes et des contextes ainsi que les fortes discontinuités temporelles laissant la plupart des développements à leur statut d'hypothèses séduisantes, matrices de recherches en cours ou à venir prometteuses.

\section{NOTES}

1. Pour une présentation récente, $c f$., entre autres, Brigitte Studer, Berthold Unfried, Irène Herrmann, eds., Parler de soi sous Staline. La construction identitaire dans le communisme des années trente, Paris, Éditions de la Maison des sciences de l'homme, 2002. 